BMJ

Open

Gastroenterology

\section{Liver stiffness by transient elastography accompanies illness severity in COVID-19}

To cite: Effenberger M, Grander C, Fritsche G, et al. Liver stiffness by transient elastography accompanies illness severity in COVID-19. BMJ Open Gastro 2020;7:e000445. doi:10.1136/ bmjgast-2020-000445

- Additional material is published online only. To view please visit the journal online (http://dx.doi.org/10.1136/ bmjgast-2020-000445).

Received 16 May 2020 Revised 13 June 2020 Accepted 19 June 2020
Check for updates

\section{(C) Author(s) (or their} employer(s)) 2020. Re-use permitted under CC BY-NC. No commercial re-use. See rights and permissions. Published by BMJ.

${ }^{1}$ Department of Internal Medicine I, Gastroenterology, Hepatology, Endocrinology and Metabolism, Medical University of Innsbruck, Innsbruck, Austria ${ }^{2}$ Department of Internal Medicine II, Infectious Disease, Pulmonology \& Rheumatology, Medical University of Innsbruck, Innsbruck, Austria

Correspondence to Professor Herbert Tilg; herbert.tilg@i-med.ac.at

\section{ABSTRACT}

Objective Severe liver damage is associated with worse outcome in COVID-19. Our aim was to explore the degree of liver damage, liver stiffness (LS) and severity of illness in patients with COVID-19.

Design We investigated 32 patients with COVID-19 admitted to the University Hospital of Innsbruck in a prospective cross-sectional study. We performed laboratory testing, liver and spleen sonography and elastography to measure organ stiffness.

Results 12 patients (38\%) showed elevated aminotransferases and gamma-glutamyltransferase levels. LS was positively correlated with elevated aminotransferase levels in patients with COVID-19 compared with those without elevated enzymes. Even mild liver damage raised LS significantly in COVID-19 as it was in patients with gastrointestinal symptoms. Furthermore, higher LS measurements were significantly associated with illness severity like pneumonia, need for mechanical ventilation, and even death.

Conclusion Transient elastography is a useful and noninvasive tool to assess onset and severity of acute liver injury in patients with COVID-19 patients. Increased LS seems to be predictive for a more severe and complicated course of disease.

\section{INTRODUCTION}

In December 2019, a series of patients with pneumonia caused by the novel severe acute respiratory syndrome coronavirus 2 (SARS-CoV-2) was reported from Wuhan, Hubei province in China. ${ }^{1}$ Since then, the coronavirus disease 2019 (COVID-19) has spread globally with over 4.5 million cases and to date more than 300000 disease related fatalities. Coronaviruses are a diverse group of large, enveloped, positive-stranded RNA viruses that cause a broad spectrum of diseases, including pneumonitis, hepatitis, nephritis, enteritis and encephalitis in animals, and several of these viruses are significant veterinary pathogens. ${ }^{2}$ Six coronavirus species have been identified to be pathogenic in humans as well. ${ }^{1}$ Among them, two coronaviruses have emerged as major

\section{Key messages}

COVID-19 is a novel pandemic.

- Liver injury is common in patients with COVID-19 ranging from $14 \%$ to $53 \%$.

- Liver stiffness by transient elastography in COVID-19 is associated with acute liver damage.

- Liver stiffness by transient elastography in COVID-19 is associated with a more severe and complicated disease course.

global health threats: the severe acute respiratory syndrome coronavirus (SARS-CoV; in 2002) that spread to 37 countries, and the Middle East respiratory syndrome coronavirus (MERS-CoV; in 2012) that reached 27 countries. ${ }^{3}$ Both, the SARS-CoV and the MERS-CoV, had a low basic reproductive number, whereas SARS-CoV-2 virus has a very high potential for community transmission and causes the current pandemic threat.

The typical symptoms of a SARS-CoV-2 infection, such as fever, cough, sore throat or dyspnoea, are well recognised and have been widely described. ${ }^{4-8}$ Additionally, the Centers of Disease Control and Prevention (CDC) announced gastrointestinal (GI) symptoms as pathognomonic in COVID-19. ${ }^{9}$ Little is known about SARS-CoV-2 inducedliver diseases, although abnormalities of liver function indexes are common in patients with COVID-19. ${ }^{6}$ 10-12

Transient elastography (TE) is a widely used non-invasive tool to measure liver stiffness (LS). LS measurements are a sensitive method to detect liver damage, and increased LS values are seen in compromised liver tissue like in chronic and in acute hepatitis. ${ }^{13}$ We took advantage of TE to investigate LS in a cohort of patients with COVID-19. 


\section{MATERIALS AND METHODS \\ Patients}

We prospectively included 32 inpatients at the University Hospital of Innsbruck, Austria, in this study. SARS-CoV-2 infection was confirmed by real-time PCR from nasopharyngeal specimens as recommended by the CDC (DeKalb, Georgia). ${ }^{14}$ A pre-existing chronic liver disease could be excluded in all patients, except in three with either hepatitis C and successful antiviral therapy or signs of metabolic associated fatty liver disease (MAFLD) at examination day (steatosis grade 1). Liver enzymes were reported normal in all patients prior to the actual admission. The median onset of COVID-19 symptoms before admission was $2.8( \pm 1.7)$ days. Fever was defined as body temperature $\geq 37.3^{\circ} \mathrm{C}$, and dyspnoea was defined by a respiratory rate $\geq 20$ breaths/min and resting finger oxygen saturation $\leq 93 \% .{ }^{15}$ The median time on the ward before evaluation of liver integrity was $1.8( \pm 1.8)$ days. GI symptoms were recorded right away at hospitalisation, and liver damage was defined by elevated levels of aspartate aminotransferase (AST; $\geq 30 \mathrm{U} / \mathrm{L}$ ) and alanine aminotransferase (ALT; $\geq 50 \mathrm{U} / \mathrm{L}$ ). Potential cofounders of elevated transaminases, including creatine kinase $(\mathrm{CK} ; \mathrm{U} / \mathrm{L})$, troponin $\mathrm{T}(\mathrm{ng} / \mathrm{mL})$ and creatinine $(\mathrm{mg} /$ $\mathrm{dL}$ ), were recorded and analysed. Laboratory tests for this study were done the same day when abdominal ultrasound (US) examination and TE were performed. We enrolled 69 patients with COVID-19 for this study. In two patients, TE of the spleen was not feasible, and patients were therefore excluded. Furthermore, eight patients with a body mass index $>28 \mathrm{~kg} / \mathrm{m}^{2}$, three patients with untreated arterial hypertension $>140 / 90 \mathrm{~mm} \mathrm{Hg},{ }^{16}$ nine patients with a history of metabolic associated liver disease or alcoholic liver disease, five patients with alcohol intake $>20 \mathrm{~g}$ /day were excluded. Three patients with chronic viral hepatitis and six patients with a history of antibiotic or antiviral treatment 3 months prior to the study were excluded. ${ }^{17}$ Current intensive care unit (ICU) patients or patients that were treated at an ICU for what reason ever within the last 3 months were excluded from this study. The exclusion criteria are listed in online supplementary figure 1 . The definition of diarrhoea was the passing of loose stools $>3$ times per day and vomiting was defined by $\geq 1$ per day. Two patients received antibiotics (levofloxacin or piperacillin/tazobactam), one patient a combination of piperacillin/tazobactam and antiviral favipiravir therapy and one patient just favipiravir therapy for COVID-19.

\section{US, TE and controlled attenuation parameter (CAP) of the liver}

Two experienced physicians (each $>3000$ US exams and LS measurements) performed the US examinations with the Philips EPIQ 5 (Philips Corporation, Amsterdam, The Netherlands) and the LS measurements and CAP with a FibroScan (EchoSens, Paris, France) device. ${ }^{18} 19$ The target area in the right liver lobe was defined to be $6 \mathrm{~cm}$ in depth and excludes major vascular structures. LS is given in kilopascal $(\mathrm{kPa})$, and a value $>5 \mathrm{kPa}$ was considered to be elevated and to reflect acute liver damage. ${ }^{20-22}$ According to current The European Association for the Study of the Liver (EASL) Guidelines on non-invasive tests for evaluation of liver disease severity and fibrosis, only procedures with a success rate of at least $60 \%$ and an IQR/ median ratio of less than $30 \%$ were included. ${ }^{20}$ In our study, the success rate of LS measurement per patient was 93\% (range $61 \%-100 \%$ ), and the average IQR/median ratio was $18 \%$ (range $2 \%-29 \%$ ). All patients were in fasting state.

\section{TE of the spleen}

Spleen stiffness was assessed using the same methodology as for liver elastography. Although the Fibroscan device is not approved for spleen stiffness measurements, there are several studies published on evaluating and using Fibroscan for spleen stiffness measurements as well. ${ }^{2324}$ The quality criteria (IQR/median ratio, success rate and number of successful measurements) used for spleen stiffness were the same as used for LS.

\section{Data analyses}

Data are expressed as mean $\pm \mathrm{SD}$ or as median with range and were compared using either the twosampled Student's t-test or the Wilcoxon signed ranking test, according to data distribution. Percentages are compared using the $\chi^{2}$ test or the Fisher's exact test where appropriate. Multivariate linear regression by liver transaminases and LS measurement was performed. The correlation between LS and the extent of inflammation was estimated using the Spearman's p coefficient. The significance level was set at 0.05 , and all $p$ values were two tailed. Statistical analyses were performed with IBM SPSS Statistics V.19.

\section{RESULTS}

\section{Medical history and comorbidities}

There was no obvious difference regarding the comorbidities and the medical history between patients' groups with or without acute liver damage on SARS-CoV2 infection (table 1).

\section{Symptoms associated with SARS-CoV-2 infection}

The group with acute liver damage was compared with the group without liver distress with regard to major clinical symptoms associated with a SARS-CoV-2 infection. Interestingly, COVID-19 patients with liver damage showed significantly more vomiting $(\mathrm{p}=0.001)$ and a higher rate of diarrhoea $(\mathrm{p}=0.02)$ and more often pulmonary opacities as a sign of COVID-19 pneumonitis $(\mathrm{p}=0.02)$ (table 1).

\section{US, TE and biochemical markers in patients with COVID-19}

Patients were grouped according to their LS values. Doppler US examination of the portal vein and the hepatic artery was normal in all patients, and none of the patients showed US signs suggestive for liver cirrhosis. 
Table 1 Medical history and COVID-19 associated symptoms

\begin{tabular}{|c|c|c|c|}
\hline & $\begin{array}{l}\text { No liver damage } \\
(\mathrm{LS}<5 \mathrm{kPa}) \mathrm{n}=20\end{array}$ & $\begin{array}{l}\text { Liver damage } \\
(\mathrm{LS}>5 \mathrm{kPa}) \mathrm{n}=12\end{array}$ & $P$ value \\
\hline Age & $69.9( \pm 16.2)$ & $73.5( \pm 13.9)$ & 0.76 \\
\hline Sex (male) & $35 \%$ & $50 \%$ & 0.82 \\
\hline Smoker & $25 \%$ & $42 \%$ & 0.66 \\
\hline Allergies & $5 \%$ & $8 \%$ & 0.32 \\
\hline Malignant disease & $15 \%$ & $16 \%$ & 0.93 \\
\hline Hypertension & $35 \%$ & $41 \%$ & 0.54 \\
\hline Diabetes & $10 \%$ & $16 \%$ & 0.75 \\
\hline Chronic liver disease & $10 \%{ }^{*} \dagger$ & $8 \% *$ & 0.34 \\
\hline Chronic heart disease & $30 \% \neq \S$ & $8 \% \neq \S$ & 0.06 \\
\hline Pregnancy & $0 \%$ & $0 \%$ & - \\
\hline COPD & $5 \%$ & $8 \%$ & 0.33 \\
\hline Immunosuppression & $5 \%$ & $8 \%$ & 0.22 \\
\hline Fever $\left(\geq 37.3^{\circ} \mathrm{C}\right)$ & $70 \%$ & $83 \%$ & 0.94 \\
\hline Dyspnoea & $60 \%$ & $75 \%$ & 0.52 \\
\hline Cough & $80 \%$ & $92 \%$ & 0.23 \\
\hline Sputum & $35 \%$ & $58 \%$ & 0.81 \\
\hline Haemoptysis & $0 \%$ & $0 \%$ & -- \\
\hline Sore throat & $70 \%$ & $75 \%$ & 0.92 \\
\hline Nasal obstruction & $55 \%$ & $75 \%$ & 0.74 \\
\hline Muscle ache & $20 \%$ & $42 \%$ & 0.70 \\
\hline Fatigue & $60 \%$ & $92 \%$ & 0.31 \\
\hline Shortness of breath & $50 \%$ & $67 \%$ & 0.93 \\
\hline Nausea & $60 \%$ & $83 \%$ & 0.85 \\
\hline Vomiting & $0 \%$ & $60 \%$ & $0.001^{*}$ \\
\hline Diarrhoea & $5 \%$ & $75 \%$ & $0.02^{*}$ \\
\hline X-ray (opacities) & $30 \%$ & $90 \%$ & $0.02^{*}$ \\
\hline Antibiotic therapy & $10 \%$ & $8 \%$ & 0.85 \\
\hline Antiviral therapy & $5 \%$ & $8 \%$ & 0.31 \\
\hline
\end{tabular}

bold indicates statistical singificant.

${ }^{*}$ MAFLD $(n=2)$.

†Chronic hepatitis $C$ infection after successful antiviral therapy $(n=1)$.

$\ddagger$ Chronic heart failure $(n=3)$.

$\S$ Coronary heart disease $(n=4)$.

COPD, chronic obstructive pulmonary disease; LS, liver stiffness; MAFLD, metabolic associated fatty liver disease.

CAP was performed to rule out significant hepatic steatosis. The overall CAP was $212.8 \pm 69.2 \mathrm{~dB} / \mathrm{m}$ with no difference between the two groups. Steatosis grade 1 was found in two patients. At the time of enrolment, no patient showed clinical or biochemical features of fulminant hepatitis, and there was no significant difference in spleen size. Patients with acute liver damage had a significantly stiffer liver and elevated aminotransferases and gamma-glutamyltransferase (GGT) levels. In these patients, the overall ferritin levels almost tripled compared with those without liver damage (table 2).

\section{Correlation of AST/ALT, ferritin and LS}

LS was significantly higher in COVID-19 patients with elevated aminotransferases $(\mathrm{p}=0.001)$ (figure 1A). Serum levels of the inflammation marker ferritin were also significantly higher in patients with elevated transferase levels $(\mathrm{p}<0.05)$ (figure 1B). To cut it down to the level of AST or ALT, we correlated both with the degree of LS and found a strong and significant correlation between LS and AST $(r=0.58 ; \mathrm{p}<0.001)$ (figure $1 \mathrm{C})$ and ALT $(\mathrm{r}=0.75 ; \mathrm{p}<0.001)$ (figure 1D) levels. However, no such correlation was seen with $\mathrm{C}$ reactive protein levels (data not shown). No cofounders were associated with LS or elevated transaminases (online supplementary figure 2). 
Table 2 COVID-19 associated biochemical markers, LS and clinical course

\begin{tabular}{|c|c|c|c|}
\hline & $\begin{array}{l}\text { No liver damage } \\
(\mathrm{LS}<5 \mathrm{kPa}) \mathrm{n}=20\end{array}$ & $\begin{array}{l}\text { Liver damage } \\
(\mathrm{LS}>5 \mathrm{kPa}) \mathrm{n}=12\end{array}$ & $P$ value \\
\hline Spleen size $(\mathrm{cm})$ & $10.8( \pm 2.1)$ & $11.1( \pm 1.9)$ & 0.44 \\
\hline Liver stiffness (kPA) & $3.4( \pm 1.2)$ & $7.8( \pm 1.8)$ & $0.001^{*}$ \\
\hline IQR/M liver & $0.5( \pm 0.3)$ & $1.5( \pm 0.4)$ & n.a. \\
\hline $\mathrm{CAP}(\mathrm{dB} / \mathrm{m})$ & $213.1( \pm 61.5)$ & $212.2( \pm 80.4)$ & 0.70 \\
\hline Spleen stiffness (kPA) & $28.1( \pm 19.8)$ & $30.4( \pm 10.7)$ & 0.78 \\
\hline IQR/M spleen & $0.6( \pm 0.2)$ & $8.6( \pm 3.7)$ & n.a. \\
\hline Bilirubin (mg/dL) & $0.43( \pm 0.22)$ & $0.42( \pm 0.2)$ & 0.43 \\
\hline AST (U/L) & $19.5( \pm 5.3)$ & $67.1( \pm 31.5)$ & $0.001^{*}$ \\
\hline ALT (U/L) & $31.3( \pm 8.3)$ & $76.3(30.6)$ & $0.001^{*}$ \\
\hline GGT (U/L) & $31.3( \pm 14.3)$ & $92.3( \pm 51.4)$ & $0.001^{*}$ \\
\hline Alkaline phosphatase (U/L) & $255.6( \pm 59.6)$ & $306.4( \pm 112.5)$ & 0.12 \\
\hline Creatine kinase $(\mathrm{U} / \mathrm{L})$ & $118.6( \pm 58.7)$ & $96.5( \pm 42.9)$ & 0.73 \\
\hline Troponin T (ng/L) & $18.2( \pm 13.2)$ & $12.1( \pm 4.2)$ & 0.62 \\
\hline Creatinine $(\mathrm{mg} / \mathrm{dL})$ & $0.9( \pm 0.3)$ & $0.9( \pm 0.3)$ & $>0.99$ \\
\hline $\operatorname{BMI}\left(\mathrm{kg} / \mathrm{m}^{2}\right)$ & $24.1( \pm 3.2)$ & $24.7( \pm 2.7)$ & 0.58 \\
\hline Max. AST (U/L) & $49.6( \pm 21.3)$ & $83.7( \pm 27.2)$ & $0.001^{*}$ \\
\hline Max. ALT (U/L) & $46.6( \pm 13.6)$ & $72.5( \pm 26.2)$ & $0.001^{*}$ \\
\hline $\mathrm{SBP}(\mathrm{mm} \mathrm{Hg})^{*}$ & $115.7( \pm 7.6)$ & $115.1( \pm 11.1)$ & 0.99 \\
\hline $\operatorname{MBP}(\mathrm{mm} \mathrm{Hg})^{*}$ & $91.6( \pm 7.4)$ & $92( \pm 9.2)$ & 0.58 \\
\hline $\mathrm{DBP}(\mathrm{mm} \mathrm{Hg})^{\star}$ & $67.5( \pm 9.5)$ & $68.3( \pm 13.4)$ & 0.67 \\
\hline LDH (U/L) & $72.5( \pm 33.5)$ & $79.9( \pm 28.8)$ & 0.54 \\
\hline $\mathrm{CRP}(\mathrm{mg} / \mathrm{dL})$ & $5.7( \pm 4.5)$ & $5.1( \pm 3.0)$ & 0.70 \\
\hline Leucocytes (g/L) & $5.0( \pm 2.1)$ & $5.9( \pm 3.9)$ & 0.41 \\
\hline Haemoglobin $(g / L)$ & $127.3( \pm 15.3)$ & $125.1( \pm 15.9)$ & 0.70 \\
\hline Platelet count $\left(10^{3} / \mathrm{\mu L}\right)$ & $226.1( \pm 89.4)$ & $233.7( \pm 87.5)$ & 0.82 \\
\hline Quick \% & $96.1( \pm 10.2)$ & $101,8( \pm 14.8)$ & 0.23 \\
\hline Ferritin $(\mu \mathrm{g} / \mathrm{L})$ & $409.1( \pm 357.8)$ & $1019.8( \pm 761.2)$ & $0.05^{*}$ \\
\hline Onset of symptoms before admission to hospital (days) & $2.4( \pm 1.3)$ & $2.8( \pm 1.7)$ & 0.61 \\
\hline Length of stay (days) & $8( \pm 1.4)$ & $15( \pm 7)$ & $0.001^{*}$ \\
\hline Admission to ICU & $0 \%$ & $25 \%$ & $0.007^{\star}$ \\
\hline Mortality & $0 \%$ & $17 \%$ & $0.001^{*}$ \\
\hline
\end{tabular}

bold indicates statistical significant.

*SBP, MBP and DBP are given as mean \pm SD during hospital stay.

ALT, alanine transferase; AST, alanine transferase; BMI, body mass index; CAP, controlled attenuation parameter; CRP, C reactive protein;

DBP, diastolic blood pressure; GGT, gamma glutamyl transferase; IQR/M, IQR/median value; LS, liver stiffness; MBP, mean blood pressure;

SBP, systolic blood pressure.

LS in symptomatic patients with COVID-19

LS was determined in patients suffering from radiologically proven COVID-19 pneumonitis and in those with GI symptoms like vomiting or diarrhoea. Interestingly, LS was increased in patients with pneumonitis compared with those without pulmonary opacities $(\mathrm{p}<0.05)$ (figure 2A). This increase in LS was even more pronounced in COVID-19 patients with GI symptoms $(p<0.05)$ (figure 2BC). Spleen stiffness was neither associated with transaminases nor with pneumonitis or GI symptoms (data not shown).
LS and clinical course

Most importantly, LS could be correlated with clinical course of illness. COVID-19 patients with LS-proven liver damage had an almost doubled length of stay in the hospital $(\mathrm{p}<0.001, \mathrm{r}=0632)$ and was more accurate than AST $(\mathrm{p}<0.01, \mathrm{r}=0.258)$ or ALT $(\mathrm{p}<0.01, \mathrm{r}=0.372)$ (figure 3). They also needed more often admission to ICU $(p=0.007)$ and even the mortality rate was higher $(\mathrm{p}=0.001)$. No differences were seen in this context regarding the onset of symptoms prior to hospitalisation (table 2). 


\section{Figure 1:}
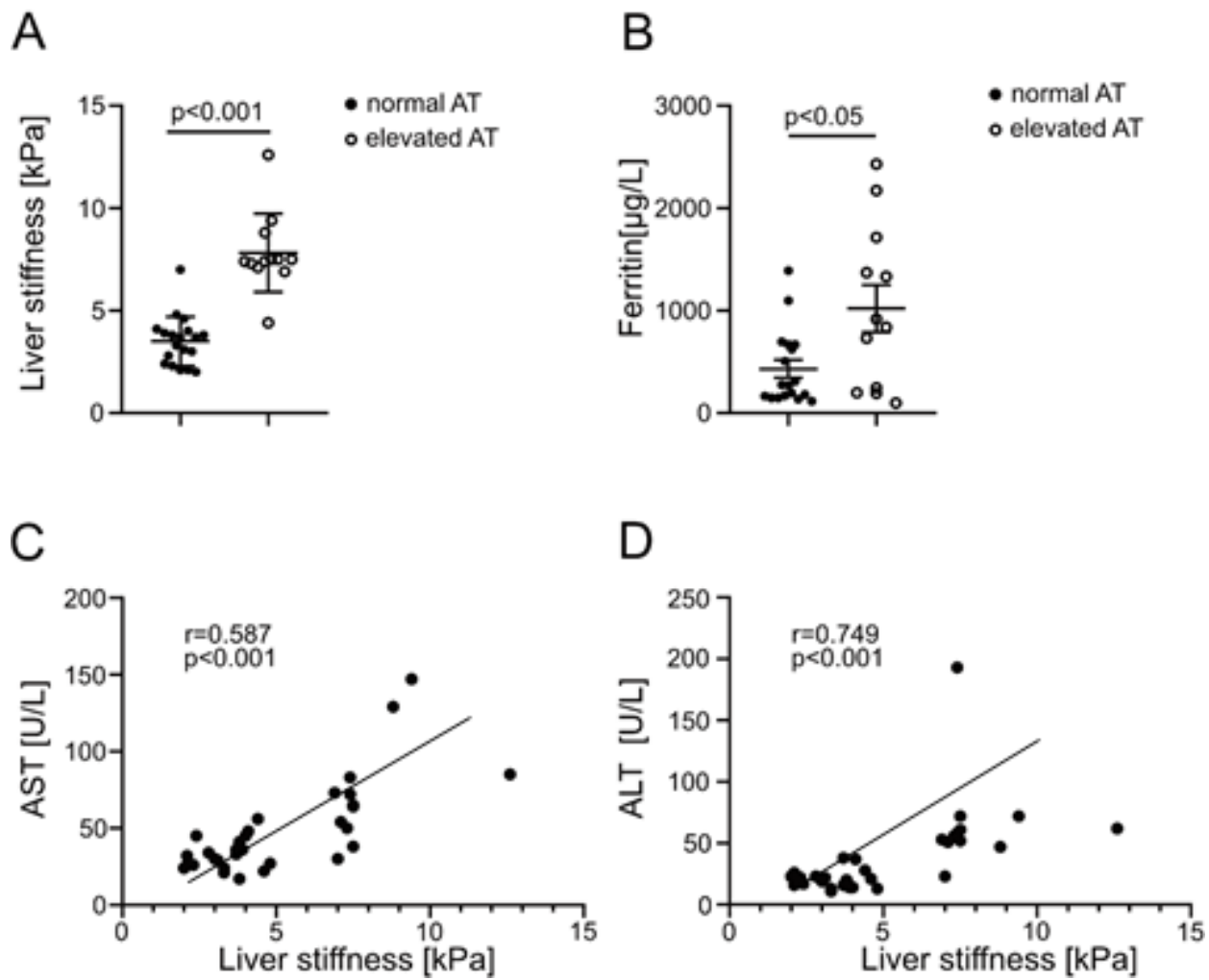

Figure 1 LS, transaminases and ferritin assessment in patients with COVID-19. LS is given in kPa and was compared with serum transaminases (panel A). Ferritin, as an acute phase protein, is given in $\mu \mathrm{g} / \mathrm{L}$ and is compared with serum transaminases (panel B). Panels $C$ and D show the correlation of LS in $\mathrm{kPa}$ to transaminases in $\mathrm{U} / \mathrm{L}$. ALT, alanine transferase; AST, alanine transferase; LS, liver stiffness.

\section{DISCUSSION}

Elevated liver enzymes have been described in COVID-19 cohorts between $17 \%$ and $57 \%$ of affected individuals. In our adult patients with COVID-19, 38\% presented with increased serum AST/ALT levels as one sign of acute liver damage. Although we investigated liver involvement in Caucasian COVID-19, our data are in agreement with various recent publications and therefore do support the assumption that our cohort is representative for typical patients with COVID-19. ${ }^{1469}$ Although the above-mentioned studies emphasised that liver injury is a common complication of COVID-19, solely laboratory tests were used to ascertain acute liver damage, but no other advanced and accepted method was used to finally prove it. We used LS measurements and the linear correlation between LS and direct markers of acute liver damage (AST, ALT and GGT) supports the suitability of LS measurements to ensure liver involvement in COVID-19.

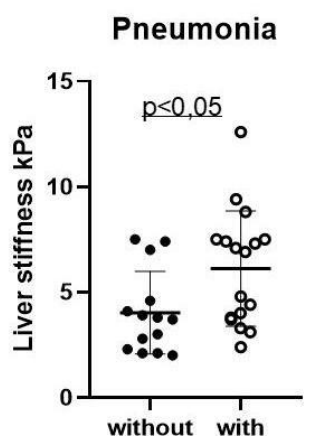

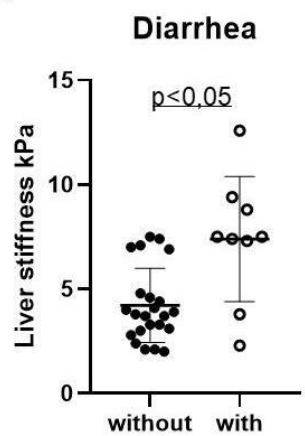

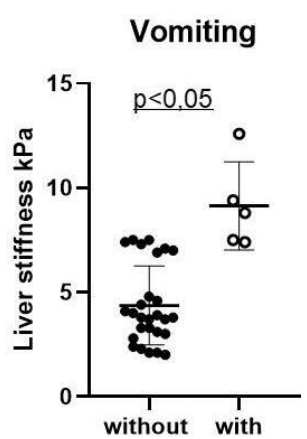

Figure 2 LS, pneumonia and Gl symptoms assessment in patients with COVID-19. LS is given in kPa and was compared with pneumonia (panel A). Panels B and C show the correlation of LS in kPa to diarrhoea (panel B) and vomiting (panel C). GI, gastrointestinal; LS, liver stiffness. 


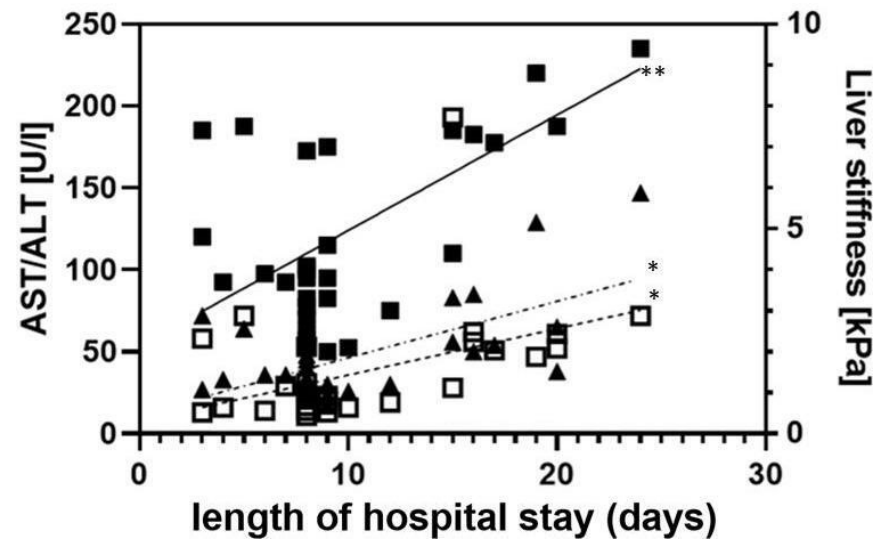

Figure 3 LS, AST and ALT and duration of hospital stay in patients with COVID-19. LS is given in $\mathrm{kPa}$, AST and ALT are given in $U / L$ and hospital stay is given in days. ${ }^{*} P<0.01$, ${ }^{* *} \mathrm{p}<0.001$. ALT, alanine aminotransferase; AST, aspartate aminotransferase; LS, liver stiffness.

TE is a well-established clinical method for the rapid and non-invasive assessment of chronic liver diseases. ${ }^{25}$ Also, in acute hepatitis, it is generally accepted that there is a strong association between LS and disease activity. Fraquelli and coworkers ${ }^{26}$ showed a stepwise increase of LS going along with the inflammatory activity in a cohort of patients with acute on chronic liver disease, and it mimics activity of biochemical markers in patients with viral hepatitis. ${ }^{27}$ The relationship of LS and aminotransferase levels and even with the degree of histologically proven liver inflammation was demonstrated convincingly several times. ${ }^{2829}$ This and our data encourage us to deem LS measurements proper to uncover liver damage, and therefore, our findings are suggestive to propose that acute liver damage caused by COVID-19 can be detected with non-invasive LS measurements.

A recent study reported that SARS-CoV-2 infection of the liver seems to be crucial for hepatic impairment in patients with COVID-19. ${ }^{30}$ However, other papers consider the virus-triggered cytokine storm to be the driving force for liver damage in COVID-19. ${ }^{31-33}$ This concept fits the observation that patients with COVID-19 had worse outcome if they had underlying non alcoholic liver disease (NAFLD)/MAFLD, but liver uptake of the virus was not enhanced in these patients. ${ }^{34}$ Therefore, the aetiology of liver damage in COVID-19 remains unclear.

Although it is assumed that COVID-19 related liver injury is clinically of little concern, it was reported that liver injury is strongly associated with patients' outcome. ${ }^{31} 35$ ICU patients with other underlying diseases had a worse outcome with higher LS levels, ${ }^{36}$ and therefore, LS might predict outcome in patients with COVID19. This is in accordance with our findings that patients with more severe disease including pneumonia had elevated LS. Another study compared patients with MAFLD and non-invasive fibrosis scores and found a worse outcome in these patients with COVID-19. ${ }^{37}$ Even though it is difficult to make a clear statement in a small cohort, LS predicted the clinical course of our patients in terms of length of hospitalisation, the need for ICU treatment and even mortality.

To conclude, LS correlates well with liver inflammation, reflected by increased aminotransferase levels, in patients with COVID-19 and with more severe disease. We encourage non-invasive bedside LS measurements to identify patients at increased risk for a complicated course of disease.

Contributors ME and HT designed the project and wrote the paper. $\mathrm{CG}$ and $\mathrm{HZ}$ verified the analytical methods and analysed the data. CG and FH performed ultrasound diagnostic and transient elastography. GW, GF, SS, SW and RB-W contributed to patient recruitment. All authors provided critical feedback and contributed to data analysis and manuscript preparation.

Funding The authors disclosed receipt of the following financial support for the research, authorship and/or publication of this article: this work is supported by the excellence initiative VASCage (Centre for Promoting Vascular Health in the Ageing Community), an R\&D K-Centre (COMET program - Competence Centers for Excellent Technologies) funded by the Austrian Ministry for Transport, Innovation and Technology, the Austrian Ministry for Digital and Economic Affairs and the federal states Tyrol, Salzburg and Vienna. TEA was supported by the Austrian Science Fund (FWF): FP33070-B.

Competing interests None declared.

Patient consent for publication Not required.

Ethics approval The study protocol was approved by the institutional ethics commission with an amendment to AN2017-0016 369/4.21 and written informed consent was obtained from all patients.

Provenance and peer review Not commissioned; externally peer reviewed.

Data availability statement All data relevant to the study are included in the article or uploaded as supplementary information.

Open access This is an open access article distributed in accordance with the Creative Commons Attribution Non Commercial (CC BY-NC 4.0) license, which permits others to distribute, remix, adapt, build upon this work non-commercially, and license their derivative works on different terms, provided the original work is properly cited, appropriate credit is given, any changes made indicated, and the use is non-commercial. See: http://creativecommons.org/licenses/by-nc/4.0/.

ORCID iD

Maria Effenberger http://orcid.org/0000-0002-0499-9953

\section{REFERENCES}

1 Li Q, Guan X, Wu P, et al. Early transmission dynamics in Wuhan, China, of novel Coronavirus-Infected pneumonia. N Engl J Med Overseas Ed 2020;382:1199-207.

2 Sutton TC, Subbarao K. Development of animal models against emerging coronaviruses: from SARS to MERS coronavirus. Virology 2015;479-480:247-58.

3 Wu JT, Leung K, Leung GM. Nowcasting and forecasting the potential domestic and international spread of the 2019-nCoV outbreak originating in Wuhan, China: a modelling study. Lancet 2020;395:689-97.

4 Zhu N, Zhang D, Wang W, et al. A novel coronavirus from patients with pneumonia in China, 2019. N Engl J Med 2020;382:727-33.

5 Guan WJ, ZY N, Hu Y, et al. Clinical characteristics of coronavirus disease 2019 in China. N Engl J Med 2020.

6 Huang C, Wang Y, Li X, et al. Clinical features of patients infected with 2019 novel coronavirus in Wuhan, China. Lancet 2020;395:497-506.

7 Chen N, Zhou M, Dong X, et al. Epidemiological and clinical characteristics of 99 cases of 2019 novel coronavirus pneumonia in Wuhan, China: a descriptive study. Lancet 2020;395:507-13.

8 Wang D, Hu B, Hu C, et al. Clinical characteristics of 138 hospitalized patients with 2019 novel coronavirus-infected pneumonia in Wuhan, China. JAMA 2020;323:1061.

9 Jin X, Lian J-S, Hu J-H, et al. Epidemiological, clinical and virological characteristics of 74 cases of coronavirus-infected disease 2019 (COVID-19) with gastrointestinal symptoms. Gut 2020;69:1002-9. 
10 Zhang Y, Zheng L, Liu L, et al. Liver impairment in COVID-19 patients: a retrospective analysis of 115 cases from a single centre in Wuhan City, China. Liver Int 2020;10.

11 Lescure F-X, Bouadma L, Nguyen D, et al. Clinical and virological data of the first cases of COVID-19 in Europe: a case series. Lancet Infect Dis 2020;20:697-706.

12 Zhang C, Shi L, Wang F-S. Liver injury in COVID-19: management and challenges. Lancet Gastroenterol Hepatol 2020;5:428-30.

13 Cobbold JFL, Taylor-Robinson SD. Transient elastography in acute hepatitis: all that's stiff is not fibrosis. Hepatology 2008;47:370-2.

14 Pan Y, Zhang D, Yang P, et al. Viral load of SARS-CoV-2 in clinical samples. Lancet Infect Dis 2020;20:411-2.

15 Zhang J, Zhou L, Yang Y, et al. Therapeutic and triage strategies for 2019 novel coronavirus disease in fever clinics. Lancet Respir Med 2020;8:e11-12.

162018 practice guidelines for the management of arterial hypertension of the European Society of hypertension and the European Society of cardiology: ESH/ESC Task force for the management of arterial hypertension: Erratum. J Hypertens 2019;37:456.

17 Li Q, Chen L, Zhou Y. Diagnostic accuracy of liver stiffness measurement in chronic hepatitis B patients with normal or mildly elevated alanine transaminase levels. Sci Rep 2018;8:5224.

18 Lucidarme D, Foucher J, Le Bail B, et al. Factors of accuracy of transient elastography (fibroscan) for the diagnosis of liver fibrosis in chronic hepatitis C. Hepatology 2009;49:1083-9.

19 Eddowes PJ, Sasso M, Allison M, et al. Accuracy of FibroScan controlled attenuation parameter and liver stiffness measurement in assessing steatosis and fibrosis in patients with nonalcoholic fatty liver disease. Gastroenterology 2019;156:1717-30.

20 European Association for Study of Liver, Asociacion Latinoamericana para el Estudio del Higado. EASL-ALEH clinical practice guidelines: non-invasive tests for evaluation of liver disease severity and prognosis. J Hepatol 2015;63:237-64.

21 Viganò M, Massironi S, Lampertico P, et al. Transient elastography assessment of the liver stiffness dynamics during acute hepatitis $B$. Eur J Gastroenterol Hepatol 2010;22:180-4.

$22 \mathrm{Kim}$ SU, Choi GH, Han WK, et al. What are 'true normal' liver stiffness values using FibroScan?: a prospective study in healthy living liver and kidney donors in South Korea. Liver Int 2010;30:268-74.

23 Buechter M, Manka P, Theysohn JM, et al. Spleen stiffness is positively correlated with HVPG and decreases significantly after tips implantation. Dig Liver Dis 2018;50:54-60.
24 Colecchia A, Ravaioli F, Marasco G, et al. A combined model based on spleen stiffness measurement and Baveno VI criteria to rule out high-risk varices in advanced chronic liver disease. $J$ Hepatol 2018;69:308-17.

25 Singh S, Muir AJ, Dieterich DT, et al. American gastroenterological association Institute technical review on the role of elastography in chronic liver diseases. Gastroenterology 2017;152:1544-77.

26 Fraquelli M, Rigamonti C, Casazza G, et al. Reproducibility of transient elastography in the evaluation of liver fibrosis in patients with chronic liver disease. Gut 2007;56:968-73.

27 Coco B, Oliveri F, Maina AM, et al. Transient elastography: a new surrogate marker of liver fibrosis influenced by major changes of transaminases. J Viral Hepat 2007;14:360-9.

28 Sagir A, Erhardt A, Schmitt M, et al. Transient elastography is unreliable for detection of cirrhosis in patients with acute liver damage. Hepatology 2008;47:592-5.

29 Arena U, Vizzutti F, Corti G, et al. Acute viral hepatitis increases liver stiffness values measured by transient elastography. Hepatology 2008;47:380-4.

30 Aden K, Rehman A, Waschina S, et al. Metabolic Functions of Gut Microbes Associate With Efficacy of Tumor Necrosis Factor Antagonists in Patients With Inflammatory Bowel Diseases. Gastroenterology 2019;157:1279-92.

31 Bangash MN, Patel J, Parekh D. COVID-19 and the liver: little cause for concern. Lancet Gastroenterol Hepatol 2020;5:529-30.

32 Tian S, Xiong Y, Liu H, et al. Pathological study of the 2019 novel coronavirus disease (COVID-19) through postmortem core biopsies. Mod Pathol 2020;33:1007-14.

33 Hanley B, Lucas SB, Youd E, et al. Autopsy in suspected COVID-19 cases. J Clin Pathol 2020;73:239-42.

34 Ji D, Xu J, Qin E, et al. Reply to: 'No evidence for an increased liver uptake of SARS-CoV-2 in metabolic-associated fatty liver disease'. J Hepatol 2020.

35 Chen P, Lei J, Wu Y, et al. Liver impairment associated with disease progression in COVID-19 patients. Liver Int 2020. doi:10.1111/ liv. 14481

36 Koch A, Horn A, Dückers H, et al. Increased liver stiffness denotes hepatic dysfunction and mortality risk in critically ill non-cirrhotic patients at a medical ICU. Crit Care 2011;15:R266.

37 Tilg H. Diet and intestinal immunity. N Engl J Med 2012;366:181-3. 